\title{
Examining the Relationship between Clean/Fossil Energy Consumption and Sustainable Development
}

\author{
Sen Qiao, Wei Jun Tong, Liang Zhan and Hsinghung Chen ${ }^{*}$ \\ School of Business, Macau University of Science and Technology, Macau, China \\ ${ }^{*}$ Corresponding author
}

\begin{abstract}
Clean Energy including natural gas, hydropower, and nuclear energy, as well as fossil energy including petroleum and coal are the most important energy consumption in China. Although important, the research on the relationship between clean/fossil energy consumption and sustainable development has only been done limitedly. Some papers have used Granger causality and employed panel co-integration test and panel error correction model to study the related topic. Thus, this paper expects to examine the causal relationship of clean/fossil energy consumption with economic growth, environmental issues, and social problems.
\end{abstract}

Keywords-component; Clean and fossil energy consumption; sustainable development; social development; economic growth

\section{INTRODUCTION}

China has shown sustained economic growth at an average annual rate of $9.0 \%$ since its economic reforms beginning in the 1980s (Yang, 2010) [27]. Although the average income per capita is expected to grow more than triple from 2005 to 2020, many evidences show that the economic expansion has induced a substantial increase in energy consumption (Apergis and Payne, 2010; Wang et al., 2011; Dergiades et al., 2013; Zhang et al., 2013) [1,23,7,28]. In fact, China consumed 2,972 million tons of oil equivalent of primary energy including $83.5 \%$ of fossil energy and $16.5 \%$ of clean energy, accounting for $23 \%$ of the world's total in 2014, and the consumption in China overpassed that in the USA since 2010 (BP, 2015) [5]. Netherlands Environmental Assessment Agency announced that carbon dioxide emissions of China had surpassed those of the US in 2006, making China the largest carbon emitter (BP, 2008; $\mathrm{Ma}$ and $\mathrm{He}, 2008)[3,18] . \mathrm{CO}_{2}$ emissions in China kept increasing from 7,945, 8,660, to 9,208 million tons in 2011, 2012, and 2013, respectively (BP, 2014) [4]. As a result, half of cities in China cannot meet air quality standards, and one third of its land is affected by acid rain (EIA, 2012) [9]. The substantial economic growth has resulted in negative side effects including environmental degradation (such as climate change, forest degradation through acid rain) and social problems (such as educational shortfalls and increasing crime rates caused by migration). One instrument to alleviate the negative socio-economic and environmental impacts is to integrate economic, environmental and social policy into a national sustainable development strategy (Klemmer, 1994; Li and Oberheitmann, 2009; Bhattacharyya, 2012) [14,17,2]. Thus, sustainable development strategy is necessary for China.

\section{LITERATURE REVIEW}

There are more than 100 definitions for sustainable development (GDRC, 2005) [10]. From Brundtland report, development that meets the needs of the present without compromising the ability of future generations to meet their own needs is the most frequently used definition for sustainable development (GDRC, 2005) [10]. Generally speaking, sustainable development is assessed from three dimensions: economy, ecology and social dimensions (Klemmer, 1994) [14]. The level of sustainable development for alternative energy has been measured by certain indicators, such as energy efficiency, carbon dioxide emission intensities and social fairness outcomes (Li and Oberheitmann, 2009) [17]. Sustainable development strategy in China is embedded in the efforts to transform China into a modern country with the need for harmony among the environment, society, and economy (Bhattacharyya, 2012) [2]. Then, the purpose of this paper is to examine, from the perspective of clean and fossil energy, the quantitative context of the economic development and subsequent growth-related environmental and social problems.

The energy consumption and economic growth nexus have attracted a considerable amount of academic interests since the emergence of the oil shocks in 1970s (Wolde-Rufael and Menyah, 2011; Paul and Uddin, 2011) [26,21]. After the seminal work by Kraft and Kraft (1978), whose findings showed that it was difficult for all countries to carry out a unique energy policy recommendation for economic growth, the relevant literature has provided mixed and conflicting evidence with respect to this relationship [15]. For instance, neutrality hypothesis indicates that if there is no causality between these two variables, economic growth will be influenced by energy conservation policy with small effect or even no effect. However, the so-called growth hypothesis is established when uni-directional causality runs from consumption to growth. Under this circumstance, the link between energy consumption and economic growth is negative. On the other hand, the conservation hypothesis holds if causality runs only from GDP growth to energy consumption. Thus, the energy conservation policy may be adopted without considering the negative effect on GDP growth. Lastly, in the case of bi-directional causality, the feedback hypothesis suggests that it is significant to take the interdependent relationship between energy consumption and growth into consideration when drawing up policies. There is plenty of research in this regard, and the identification of the relationship at the disaggregated level becomes important because the effect of economic growth varies with different types of energy (Kum 
et al., 2012) [16]. A new set of literature has appeared in order to study the relationship of various types of energy consumption, including electricity, coal, natural gas and gasoline, with economic growth (Omu et al., 2013) [20].

\section{Methodology}

\section{A. Proposed Hypotheses}

In order to examine the causal relationship of Clean/Fossil Energy consumption with economic growth, environmental issues and social problems, the following hypotheses are made, while the paper will employ panel data models to simulate the multi-variable regressions.

Many studies have shown that a substantial increase in energy consumption, especially in renewable energy consumption, has a significant relationship with economic development (Apergis and Payne, 2010) [1].

Hypothesis (a): The causal relationship of natural logarithm of real GDP per capita with change of clean energy consumption should be positive in a specific period.

Empirical evidence suggests that there is a bi-directional causal relationship between industrial and residential energy consumption to real GDP (Tsani, 2010) [22].

Hypothesis (b): The causal relationship of natural logarithm of real GDP per capita with change of fossil fuelbased energy consumption should be positive in a specific period.

Menegaki (2011) used annual panel data ranging from 1997 to 2007 for 27 European countries to examine the causal relationship of real GDP per capita with greenhouse emissions equivalents with base year 1990, and concluded that their relationship was apparently opposite [19].

Hypothesis (c): The causal relationship of natural logarithm of real GDP per capita with change of GHG emissions should be negative in a specific period.

The results indicate that a natural gas boom should increase salary income because of the combination of a greater demand for labor, an increase in the number of jobs, and a raise in the rent payments to private and public resource owners (Weber, 2012) [25].

Hypothesis (d): The causal relationship of natural logarithm of real GDP per capita with change of income per capita should be positive in a specific period.

The existence of supporting schemes for renewable energy represents an opportunity to reduce the risk by ensuring a fixed income for a certain period of time, and reflects the need to ensure the interests from private investors for technological innovation (Carneiro and Ferreira, 2012) [6].

Hypothesis (e): The causal relationship of natural logarithm of real GDP per capita with change of real gross fixed capital formation should be positive in a specific period.

Wolde-Rufael and Menyah (2011) examined the causal relationship of the change of GDP per capita with the change of labor force and other parameters, and concluded that the relationship was positive with significance [26].

Hypothesis ( $f$ ): The causal relationship of natural logarithm of real GDP per capita with change of labor force should be positive in a specific period.

\section{B. Research Methodology}

In this study, panel data is applied due to three major reasons. First, each province in China has quite different cultural backgrounds and specific characteristics. The use of panel data can effectively control the heterogeneity of individual province. Second, since only 15 provinces/places have sufficient data, there are not enough observations for regression. The employment of panel data can solve the problem. Third, from the perspective of econometrical study, panel data can provide us more degrees of freedom, more information, more variation, and less collinearity (Wang, 2008) [24]. Accordingly, the paper will employ panel data models to simulate the multi-variable regressions. From the proposed hypotheses, we have the following equation:

$$
y_{i, t}=\alpha_{i}+\sum_{i}^{k} \beta_{i, t} X_{i, t}+\delta_{i, t}
$$

where $y_{i, t}=$ natural logarithm of real GDP per capita in province $i$ during $t$ and $t-1$;

$\alpha_{i}=$ a regression constant for province $i$;

$\beta_{i, t}=$ a regression coefficient in province $i$ at $t$;

$X_{i, t}=$ independent variables such as natural logarithm of fossil-based energy consumption or change of labor force; and

$\delta_{i, t}=$ a random residual in province $i$ at $t$.

However, because the available time span is only 10 years, a simpler equation is employed to obtain the overall rather than individual relationships among variables:

$$
y_{i, t}=\alpha_{i}+\sum_{i}^{k} \beta_{i} X_{i, t}+\varepsilon_{i, t}
$$

Then, the proposed equation can be further represented by the following equation:

$$
\begin{aligned}
y_{i, t}= & \alpha_{i}+\beta_{1} X_{1(i, t)}+\beta_{2} X_{2(i, t)}+\beta_{3} X_{3(i, t)}+\beta_{4} X_{4(i, t)}+ \\
& \beta_{5} X_{5(i, t)}+\beta_{5} X_{5(i, t)}+\varepsilon_{i, t}
\end{aligned}
$$

where $\alpha_{i}=\alpha+\alpha^{*}$

$y_{i, t}=$ natural logarithm of real GDP per capita in province $i$ during $t$ and $t-1$; 
$X_{1(i, t)}=$ change of GHG emissions in province $i$ at $t$;

$X_{2(i, t)}=$ natural logarithm of clean energy consumption in province $i$ at $t$;

$X_{3(i, t)}=$ natural logarithm of fossil-based energy consumption in province $i$ at $t$;

$X_{4(i, t)}=$ change of income per capita in province $i$ at $t$;

$X_{5(i, t)}=$ change of fixed capital formation in province $i$ at $t$;

$X_{6(i, t)}=$ change of labor force in province $i$ at $t$;

$\varepsilon_{i, t}=$ a random residual in province $i$ at $t$;

$\alpha$ = average value of cross-section item in province $i$; and

$\alpha^{*}=$ individual deviation from average value of crosssection item in province $i$.

To examine the presence of unit roots in a series, LevinLin-Chu (LLC) test, augmented Fisher Dickey-Fuller (Fisher$\mathrm{ADF}$ ) test and Fisher Phillips-Perron (Fisher-PP) test are well accepted methods. When co-integration test is applied to verify the stability of a system, Kao residual test is well accepted (Kao and Chiang, 2000) [13]. When employing the panel data model, three alternatives are pooled ordinary least square (OLS) regression model, fixed effect (FE) regression model, and random effect (RE) regression model. When likelihood test is passed, the FE regression model is more appropriate. When Hausman test is passed, the RE regression model is more suitable. Otherwise, the OLS regression model can be used. However, if both likelihood and Hausman tests are passed (in the paper, the number of provinces $(\mathrm{N})$ is greater than the number of year (T), the FE model is more suitable if panel data is not randomly sampled (Hausman, 1978; Green, 2003) $[12,11]$. Oppositely, the RE model is more appropriate if panel data is randomly sampled.

Before simulating the regressions, several potential econometric problems need to be checked. The first one is collinearity between explanatory variables. People may have good reason to suspect a collinearity relation between variables, such as labor force and average income, because they may impact each other. This may be a critical problem if we employ just cross-sectional data. As mentioned above, panel data model can basically solve the collinearity problem. The second problem is heteroscedasticity among cross-sectional data. To solve this problem and possible cross-sectional correlation problem, we employ regressions that report Driscoll-Kraay standard errors. Such kinds of regressions are more robust if heteroscedasticity and cross-sectional correlation problems exist (Driscoll and Kraay, 1998) [8]. In addition, because the panel data in the case study has the characteristic of $N>T$, the problems of serial correlation and panel unit root may be reasonably ignored.

\section{DATA COLLECTION AND ANALysis}

This study employs panel data regression model to examine the relationship of natural gas consumption with sustainable development in China. Panel data sets include one dependant variable, real GDP per capita (unit: RMB), and six independent variables: clean energy consumption including hydropower, nuclear, and natural gas energy (unit: million tons of oil equivalent), fossil-based energy consumption including coalbased, and gasoline-based energy (unit: million tons of oil equivalent), GHG emissions (million tons), income per capita (unit: RMB) , fixed capital formation (unit: billion of RMB) and labor force (unit: 10,000 persons). The data of 15 places in China are collected from 2005 to 2014. The sampled provinces and cities include XINJIANG, QINGHAI, GANSU, SHANXI, SICHUAN, HAINAN, GUANGDONG, HUBEI, HENAN, SHANDONG, JIANGSU, HEILONG, JILIN, LIAONING, and HEBEI. The paper selects the places having the most integrated data from 2005 through 2014. The descriptive statistics and covariance analysis of all variables are presented in Table I and II, respectively. Unit root test is passed after the first order difference of all variables $(\mathrm{P}<0.01)$ and the result is shown in Table III. Kao Residual Co-integration Test is passed with a value of $\mathrm{P}$ equaling 1.25\%, and the result is shown in Table IV.

TABLE I. DESCRIPTIVE STATISTICS FOR ALL VARIABLES

\begin{tabular}{|c|l|l|l|l|l|l|l|}
\hline & GDP & Clean & Fossil & GHG & Income & Capital & Labor \\
\hline Mean & 8.961 & 23.999 & 25.108 & 0.027 & 0.113 & 0.207 & -0.017 \\
\hline Max. & 10.952 & 26.534 & 26.856 & 0.675 & 0.205 & 0.654 & 0.030 \\
\hline Min. & 5.966 & 20.410 & 22.262 & -0.202 & 0.000 & -0.107 & -0.082 \\
\hline Std. Dev. & 1.133 & 1.358 & 1.096 & 0.117 & 0.045 & 0.119 & 0.018 \\
\hline Skewness & -0.490 & -0.103 & -0.846 & 2.222 & -1.223 & 0.519 & -0.508 \\
\hline Kurtosis & 2.664 & 2.438 & 3.352 & 10.520 & 4.424 & 4.427 & 3.652 \\
\hline Obs. & 150 & 150 & 150 & 150 & 150 & 150 & 150 \\
\hline Cross sections & 15 & 15 & 15 & 15 & 15 & 15 & 15 \\
\hline
\end{tabular}

TABLE II. THE RESULTS OF COVARIANCE ANALYSIS

\begin{tabular}{|c|c|c|c|c|c|c|c|}
\hline & GDP & Clean & Fossil & GHG & Income & Capital & Labor \\
\hline GDP & 1.000 & & & & & & \\
\hline Clean & $0.091 *$ & 1.000 & & & & & \\
\hline Fossil & $0.593^{* * *}$ & $0.132 *$ & 1.000 & & & & \\
\hline GHG & $0.388^{* * *}$ & $0.061 *$ & $-0.147 * *$ & 1.000 & & & \\
\hline Income & $0.280 * * *$ & 0.040 & $0.173^{* * *}$ & $0.085 * *$ & 1.000 & & \\
\hline Capital & $0.007^{*}$ & - & $0.135 * *$ & $0.024^{*}$ & $0.543 * * *$ & 1.000 & \\
\hline Labor & -0.116 & $0.000 *$ & $-0.069 *$ & $0.029 *$ & $-0.385^{* * *}$ & $-0.181 * * *$ & 1.000 \\
\hline
\end{tabular}

\section{DISCUSSION}

Using the multivariable instrument, the paper concludes that the development of clean/fossil energy consumption integrated with the consideration of the reduction of pollutant emissions, the improvement of income per capita, the creation of new jobs, and the attraction of capital investment does make a significant contribution to sustainable development in China. In other words, the importance of these findings lies on their implications for governments to adopt strategic policies in supporting economic growth, optimizing energy structure, 
ensuring energy security, as well as in strengthening environmental protection and improving living standards.

TABLE III. THE RESULTS OF UNIT ROOT TEST

\begin{tabular}{|c|c|l|l|l|l|l|}
\hline & \multicolumn{3}{|c|}{ Level } & \multicolumn{3}{c|}{ 1st difference } \\
\hline & LLC & Fisher-ADF & Fisher-PP & LLC & Fisher-ADF & Fisher-PP \\
\hline GDP & $-4.96 * * *$ & 25.13 & $77.60^{* * *}$ & $-11.21^{* * *}$ & $88.59 * * *$ & $127.92 * * *$ \\
\hline Clean & $-23.90^{* * *}$ & $51.40^{* * *}$ & $52.11^{* * *}$ & & & \\
\hline Fossil & $-3.77 * * *$ & 17.81 & 15.46 & $-10.70^{* * *}$ & $98.90^{* * *}$ & $126.79 * * *$ \\
\hline GHG & $-7.81^{* * *}$ & $54.57 * * *$ & $54.06^{* * *}$ & & & \\
\hline Income & $-15.32 * * *$ & $138.65 * *$ & $243.57 * * *$ & & & \\
\hline Capital & $-6.19 * * *$ & $96.95 * * *$ & $141.34 * * *$ & & & \\
\hline Labor & $-8.72 * * *$ & $79.81^{* * *}$ & $104.18^{* * *}$ & & & \\
\hline
\end{tabular}

TABLE IV. THE RESULTS OF COVARIANCE ANALYSIS

\begin{tabular}{|l|c|c|}
\hline \multicolumn{2}{|l|}{ Kao Residual Co-integration Test } \\
\hline Null Hypothesis: No co-integration \\
\hline & t-Statistic & Prob. \\
\hline ADF & -2.241475 & 0.0125 \\
\hline Residual variance & 0.017783 & \\
\hline HAC variance & 0.030174 & \\
\hline
\end{tabular}

\section{REFERENCES}

[1] Apergis, N., Payne, J.E. 2010. Renewable energy consumption and economic growth: evidence from a panel of OECS countries. Energy Policy 38, 656-660.

[2] Bhattacharyya, S.C., 2012. Energy access programmes and sustainable development: a critical review and analysis. Energy for Sustainable Development 16, 260-271.

[3] British Petroleum (BP). 2008. BP statistical review of world energy. The materials can be found from the web at https://www.bp.com/statisticalreview.

[4] British Petroleum (BP). 2014. BP statistical review of world energy. The materials can be found from the web at https://www.bp.com/statisticalreview.

[5] British Petroleum (BP). 2015. BP statistical review of world energy. The materials can be found from the web at https://www.bp.com/statisticalreview.

[6] Carneiro, P., Ferreira, P. 2012. The economic, environmental and strategic value of biomass. Renewable Energy 44, 17-22.

[7] Dergiades, T., Martinopoulos, G., Tsoulfidis, L. 2013. Energy consumption and economic growth: parametric and non-parametric causality testing for the case of Greece. Energy Economics 36, 686-697.

[8] Driscoll, J., Kraay, A. 1998. Consistent covariance matrix estimation with spatially dependent panel data. Review of Economics and Statistics 80(4), 549-560.

[9] Energy Information Administration (EIA), 2012. Annual Energy Outlook 2012, U.S. Department of Energy, Washington, D.C, Available from: http://www.eia.gov/ forecasts/aeo/pdf/0383.pdf (last viewed 2014.6.3).

[10] GDRC 2005. The Global Development Research Center: SD Features definitions. Online: http://www.gdrc.org/sustdev/definitions.html (accessed 19July, 2005).

[11] Green, W.H. 2003. Econometric Analysis, $5^{\text {th }}$ ed. Prentice Hall, Upper Saddle River, New Jersey.

[12] Hausman, J. 1978. Specification tests in econometrics. Econometric 46, 1251-1271.
[13] Kao, C., Chiang, M.H. 2000. On the estimation and inference of a cointegrated regression in panel data. Advances in Econometrics 15, 179-222.

[14] Klemmer, P. 1994. Nachhaltige entwicklung-aus okonomischer sicht. Zeitschrift fur angewandte Umweltforschung (7), 14-18.

[15] Kraft J, Kraft, A. 1978. On the relationship between energy and GNP, Journal of Energy and Development 3, 401-403.

[16] Kum, H., Ocal, O., Aslan, A. 2012. The relationship among natural gas energy consumption, capital and economic growth: bootstrap-corrected causality test from G-7 countries. Renewable and Sustainable Energy Reviews 16, 2361-2365.

[17] Li, Y., Oberheitmann, A. 2009. Challenges of rapid economic growth in China: reconciling sustainable energy use, environmental stewardship and social development. Energy Policy 37, 1025-1035.

[18] Ma, C., He, L. 2008. From state monopoly to renewable portfolio: restructuring China's electrical utility. Energy Policy 36(5), 1697-1711.

[19] Menegaki A.N. 2011. Bourgas-Alexandroupolis oil pipeline; will matching institutional and regulatory contexts lead to an effective bargaining and eventual consensus? Energy Policy 39, 1277-1285.

[20] Omu, A., Choudhary, R., Boies, A. 2013. Distributed energy resource system optimization using mixed integer linear programming. Energy Policy 61, 249-266.

[21] Paul, B.P., Uddin, G.S. 2011. Energy and output dynamics in Bangladesh, Energy Economics 33, 480-487.

[22] Tsani, S.Z. 2010. Energy consumption and economic growth: a causality analysis for Greece. Energy Economics 32, 582-590.

[23] Wang, Y., Wang, Y, Zhou, J., Zhu, X., Lu, G. 2011. Energy consumption and economic growth: a multivariate casualty test. Energy Policy 39, 4399-4406.

[24] Wang, Z. 2008. Panel data model and its application in economics. Beijing: Economic Science Press, 2008.

[25] Weber, J.G. 2012. The effect of a natural gas boom on employment and income in Colorado, Texas, and Wyoming. Energy Economics 34, 15801588.

[26] Wolde-Rufael Y.C., Menyah, A.N. 2011. Growth and renewable energy in Europe: a random effect model with evidence for neutrality hypothesis. Energy Economics 33, 257-263.

[27] Yang, M. 2010. China's energy efficiency target 2010. Energy Policy 64, 561-570.

[28] Zhang, X., Wu, L., Zhang, W.R., Deng, S., Zhang Y. 2013. Evaluating the relationship among economic growth, energy consumption, air emission and air environmental protection investment in China. Renewable and Sustainable Energy Review 18, 259-270. 